\title{
Studies of release properties of ISOLDE targets*
}

\author{
K. Peräjärvi ${ }^{* *}$, U.C. Bergmann, V.N. Fedoseyev, A. Joinet, U. Köster, C. Lau ${ }^{* * *}$, J. Lettry, H. \\ Ravn, M. Santana-Leitner and the ISOLDE collaboration \\ EP-Division, CERN, 1211 Genève 23, Switzerland
}

\begin{abstract}
Off-line release rates of $\mathrm{Be}, \mathrm{Mg}, \mathrm{S}, \mathrm{Mn}$ and $\mathrm{Kr}$ from refractory materials were studied. $\mathrm{Mn}$ yields were determined from a $\mathrm{ZrO}_{2}$ target and $\mathrm{Kr}$ yields from a $\mathrm{SrO}$ and $\mathrm{ZrO}_{2}$ targets. A Monte Carlo code to optimize ISOLDE targets was introduced.
\end{abstract}

PACS: 25.40.Sc; 28.60.+S; 29.25.Rm; 61.43.Gt; 66.30.Jt; 68.43.Mn

Keywords: Target; Radioactive ion beams; Isotope separator on-line; Monte Carlo

\section{Introduction}

The Isotope Separator On-Line (ISOL) technique [1] has been in use at CERN already more than 30 years and allows to make radioactive ion-beams of $70 \%$ of the chemical elements. To maintain the attractiveness of CERN/ISOLDE and as preparation for the EURISOL project continuous development of the targets is required. This development concentrates presently on creating a more solid understanding of the performance of the target in order to reduce the decay losses and make beams of the remaining elements available. These studies have a growing importance since all chemically "easy" beams are already in use and the experiments are pursued far from the valley of beta-stability, where often one has to work with extremely short half-lives and low production cross-sections.

\footnotetext{
* Supported by the EU RTD projects EURISOL (HPRI-CT-1999-50001) and TARGISOL (HPRI-CT-200150033).

** Corresponding author. Tel.: + 4122 7674720; fax: +41 22 7678990; e-mail address: Kari.Perajarvi@cern.ch.

*** Present address: IPN Orsay, Orsay, France.
} 
In this article we concentrate onto the three different topics related to the target and ion source development. First new results from off-line target material studies are presented. The release of $\mathrm{Be}, \mathrm{Mg}, \mathrm{S}, \mathrm{Mn}$ and $\mathrm{Kr}$ is discussed. Secondly, previously unpublished $\mathrm{Mn}$ and $\mathrm{Kr}$ yields are presented. As a third topic, a short introduction is given to a new Monte Carlo code that allows to optimize the intrinsic delay time as function of target and ion-source geometry. The release of $\mathrm{Kr}$ from a $\mathrm{Nb}$ foil target is used as an example.

\section{Off-line studies}

At ISOLDE activation and radioactive tracer implantation are used to produce the samples of interest for the off-line material studies. Activation is done using the well known pneumatic transport system "rabbit" $[2,3]$. Both 1 and $1.4 \mathrm{GeV}$ protons are employed. The fractional activity after heating of the samples in vacuum $\left(p<3 \times 10^{-5}\right.$ mbar $)$ is determined by radioassay with a gamma-ray spectrometer $[2,3]$. Temperature equilibrium between the sample and the oven is reached in less than one minute [2]. Each sample is only heated once. Details of the irradiated materials are given in Table 1.

A rapid release of implanted ${ }^{7} \mathrm{Be}$ from a Ta foil was observed $(60,160$ and $260 \mathrm{keV}$ implantation energies were used corresponding to about 800,2200 and $3400 \AA$ projected ranges of $\mathrm{Be}$ in $\mathrm{Ta}[5])$. The measured fractional activities are consistent with the used implantation energies (see Fig. 1a).

The fastest release of $\mathrm{Mg}$ was observed from a $\mathrm{Ti}$ foil, see Fig. $1 \mathrm{~b}$. For $\mathrm{Mg}$ also fast desorption from $\mathrm{Ti}$ surfaces is expected (the Eichler-Miedema model [6, 7] predicts a sticking time of the order of $1 \mathrm{~ns}$ at $1600{ }^{\circ} \mathrm{C}$ ).

$\mathrm{S}$ was observed to have a fast release from $\mathrm{TiO}_{2}$ powder and felt and also from the VC powder (see Fig. 1c) (fast release from VC was reported earlier in [2]). To avoid long effusion delay times $\mathrm{S}$ should form immediately after the release a volatile molecule for instance with $\mathrm{CO}$. 
$\mathrm{Mn}$ is released most quickly from a $\mathrm{Zr}$ foil (see Fig. 1d). For Mn a slower desorption from $\mathrm{Zr}$ surfaces is expected (the Eichler-Miedema model $[6,7]$ predicts a sticking time of the order of $50 \mu$ s at $\left.1800{ }^{\circ} \mathrm{C}\right)$.

$\mathrm{Kr}$ is releasing from all the examined materials i.e. from $\mathrm{SrZrO}_{3}, \mathrm{Y}_{2} \mathrm{O}_{3}, \mathrm{Zr}, \mathrm{ZrO}_{2}, \mathrm{Nb}$ and Mo (see Fig. 1e). As an example the release of $\mathrm{Kr}$ is faster from $\mathrm{Y}_{2} \mathrm{O}_{3}$ felt than from $\mathrm{ZrO}_{2}$ felt and also the release of $\mathrm{Kr}$ is at least as fast from a $\mathrm{Zr}$ foil as from a $\mathrm{Nb}$ foil. $\mathrm{A}$ more extensive and complete study of the performed off-line measurements will be presented elsewhere [8].

\section{On-line studies}

The yields of $\mathrm{Mn}$ nuclei from a $\mathrm{ZrO}_{2}$ felt target were determined using the ISOLDE spectroscopy station [9] (this gamma-detector set-up was mainly used to determine the yields of ${ }^{48,}{ }^{49} \mathrm{Mn}$ ) and the monitoring tape-station [10] (beta counting) set-ups. The pulsed proton beam energy was $1.4 \mathrm{GeV}$. The Resonance Ionization Laser Ion Source (RILIS) [11] was used for $\mathrm{Mn}$ ionization. Compared to the former measurement with a $\mathrm{Nb}$ foil target at the General Purpose Separator (GPS) [12], the laser power focused to the High Resolution Separator (HRS) front-end was about a factor two lower which halfed the ionization efficiency. Further details are given in Table 2.

The yields of $\mathrm{Mn}$ from a $\mathrm{Nb}$ foil [12] and $\mathrm{ZrO}_{2}$ felt targets are presented in Fig. 2a. The yields are generally lower from the $\mathrm{ZrO}_{2}$ target due to the lower target thickness. Only for the most short-lived isotopes the faster release from $\mathrm{ZrO}_{2}$ overcompensates this reduction. The yields of $\mathrm{Kr}$ nuclei from $\mathrm{SrO}$ and $\mathrm{ZrO}_{2}$ targets were determined using the monitoring tape-station set-up. Both targets were connected to an ISOLDE type FEBIAD ion source using a water-cooled transfer line (MK7) [14]. The ionization efficiency of Kr was about 3 $\%$ for both ion-sources. The proton beam energy was $1.0 \mathrm{GeV}$. Further details are given in Table 2. 
The yields of $\mathrm{Kr}$ from a $\mathrm{SrO}$ and $\mathrm{ZrO}_{2}$ felt targets are presented in Fig. 2b. Observed low

${ }^{73} \mathrm{Kr}$ yield from a $\mathrm{SrO}$ target is probably due to the fluctuation of the measurement. Fig. $2 \mathrm{~b}$ together with Table 2 demonstrates that the $\mathrm{Nb}$ foil target (foil thickness $25 \mu \mathrm{m}$ ) [15] is still a competitive choice for the production of short-lived and n-deficient $\mathrm{Kr}$ isotopes like ${ }^{69} \mathrm{Kr}$ $\left(T_{1 / 2}=32(10) \mathrm{ms}[16]\right)$.

\section{Monte Carlo code}

The new Monte Carlo code admits flexible target and ion source geometries, with no limitation to the size or complexity of the system (other than CPU time consumption). Like some transport codes [17], the geometry is defined in terms of cells, enclosed by second order surfaces. Their equation coefficients and respective temperatures are defined in the input file, allowing variable temperature profiles and permitting all kind of changes without any new compilation. Moreover, it becomes easy to compose large input files from several modules (target, container, transfer line and ion source) by simply stacking one on top of the following in the input file, and by linking the interfaces. Concerning the particle generation, the user can specify in the input file the primary energy and type of effusing particles and their geometrical distribution on creation, including gaussian-like profiles.

On execution the user is offered to use several variance reduction methods. The output file includes various average figures like the number of collisions and, if wanted, individual delay times. Additionally, a complementary file is printed which expresses a compressed form of the connectivity matrix of the input geometry. It is a useful file in geometry verification. Moreover, the program uses the matrix to speed up computations.

The code has been tested in several situations where the effusion delay curve can be calculated analytically with the kinetic theory. The code yielded accurate results within the statistic error of reasonably long simulations.

At ISOLDE $1 \mathrm{GeV}$ protons are delivered in $2.4 \mu$ s long pulses. Usually in the release studies the time difference between neighboring pulses is $14.4 \mathrm{~s}$. The squares in the inset of Fig. 3 
represent the measured on-line release function of ${ }^{73} \mathrm{Kr}\left(T_{1 / 2}=29.0(10) \mathrm{s}\right.$ [18] $)$ from the $\mathrm{Nb}$ roll foil target ( $\mathrm{Nb}$ foil thickness $25 \mu \mathrm{m})$ at a temperature of $2000{ }^{\circ} \mathrm{C}$. The shape of the curve ( $N$ in the Eq. 1) can be reproduced in the calculations by combining effusion $(f)$, diffusion $(h)$ and radioactive decay $(d)$ data (see circles in the inset of Fig. 3 (Nxconstant)):

$$
\begin{aligned}
& N(k \Delta t)=d(k \Delta t) \sum_{i=0}^{k} f((k-i) \Delta t) h(i \Delta t) \Delta t+ \\
& d\left(t_{S C Y}+k \Delta t\right) \sum_{i=0}^{S C Y} f\left(t_{S C Y}+(k-i) \Delta t\right) h(i \Delta t) \Delta t
\end{aligned}
$$

In Eq. $1 f(t)$ is the effusion delay time distribution for particles released from the target into a target container at $t=0 \mathrm{~s}$. $h(t)$ determines the relative amount of effusing particles released into the target volume as a function of time. $h(t)$ term originates from the diffusion process. The $d(t)$ term corrects for decay losses. The contribution of the previous proton pulse is also included (one proton pulse per super cycle $\left(t_{\mathrm{SCY}}=14.4 \mathrm{~s}\right.$ or $16.8 \mathrm{~s}, \Delta t=1 \mathrm{~ms}$ ) is assumed [10]). Since the $N, d$ and $h$ terms are known experimentally, Eq. 1 can be used to determine the shape of the $\mathrm{Kr}$ effusion delay time distribution $f(t)$. Solid line in Fig. $3(f(t))$ together with the circles in the inset of Fig. 3 (Nxconstant) represent the outcome of this iteration process. The diffusion coefficient $9 \times 10^{-9} \mathrm{~cm}^{2} / \mathrm{s}$ was taken from [19].

The effusion of $\mathrm{Kr}$ was also computed using the Monte Carlo code described earlier. Zero sticking time on surfaces was assumed. The starting distribution of effusing particles was derived from the radial structure of the impinging proton pulse. In the simulations $12 \mathrm{Nb}$ target foil rolls (length of $1.5 \mathrm{~cm}$ ) were placed in a Ta target container (length $19.5 \mathrm{~cm}$ ) with 1 and $0.1 \mathrm{~mm}$ roll spacing. With $1 \mathrm{~mm}$ even roll spacing we have $2 \mathrm{~mm}$ gap at both ends of the target container while with $0.1 \mathrm{~mm}$ spacing we have $7 \mathrm{~mm}$ end gaps. For both geometries about 10000 particles were computed. Fig. 3 represents the outcome of these simulations; up triangles correspond to the $1 \mathrm{~mm}$ roll spacing and down triangles to the $0.1 \mathrm{~mm}$ spacing (note that all curves in Fig. 3 are normalized to the same maximum amplitude instead of equal area). These results indicate that the roll spacing is one of the important tuning 
parameters of the ISOLDE foil targets. The shape of the experimental curve would be possible to reproduce simply by tuning the spacing between the target rolls. A more extensive study will be presented elsewhere [20]. The average number of wall collisions before the exit with $1 \mathrm{~mm}$ roll spacing is about 765000 (corresponding to about $150 \mathrm{~m}$ traveled distance) and with $0.1 \mathrm{~mm}$ spacing about 3450000 (corresponding to about $615 \mathrm{~m}$ traveled distance). The suggested faster effusion of $\mathrm{Kr}$ out of the target and ion source unit with the $1 \mathrm{~mm} \mathrm{Nb}$ foil roll spacing would for example double the earlier measured ${ }^{69} \mathrm{Kr}$ yield $\sim 3 \times 10^{-4}$ at $/ \mu \mathrm{C}[21]$.

\section{Conclusions}

Even though the ISOL technique has already a long history, off-line material studies are still relevant. They provide a fairly inexpensive way to probe the properties of materials and, as was shown, they are still able to produce valuable information for the target and ion source data-base. Real on-line yields and release curves like the ones presented now are always very important since the whole operation of ISOLDE is based upon them. The introduced Monte Carlo code showed immediately its capability. In the next phase it will be extended to include diffusion etc. In addition, this code will be cross-checked with the dedicated off-line effusion delay time measurements.

\section{References}

H.L. Ravn and B.W. Allardyce, On-line mass separators, vol. 8 of Treatise on Heavy-Ion Science, Plenum Press, New York (1989).

L.C. Carraz et al., Nucl. Instr. and Meth. 148 (1978) 217.

P. Hoff et al., Nucl. Instr. and Meth. 221 (1984) 313.

U. Köster et al., Proc. of EMIS-14, To be published.

J.F. Ziegler et al., The stopping and range of ions in matter, vol. 1

(Pergamon, New York, 1985). 

Tech Publications, Switzerland (1998). B. Eichler et al., 'Adsorption flüchtiger Metalle auf metallischen Oberflächen und Möglichkeiten ihrer Anwendung in der Kernchemie - Berechnung der Adsorptionsenthalpien der Actinoide.' Tech. Rep. ZfK-560, Zentralinstitut für Kernforschung, Rossendorf (1985).

A. Joinet et al., Nucl. Instr. and Meth. A, To be published.

L. Weissman et al., Phys. Rev. C 65 (2002) 044321.

J. Lettry et al., Nucl. Instr. and Meth. B 126 (1997) 130.

V.N. Fedoseyev et al., Hyp. Inter. 127 (2000) 409.

M. Oinonen et al., Hyp. Inter. 127 (2000) 431.

U.C. Bergmann et al., Proc. of EMIS-14, To be published.

T. Bjørnstad et al., Nucl. Instr. and Meth. B26 (1987) 174.

M. Oinonen et al., Proc. of ISOL01, in press.

X.J. Xu et al., Phys. Rev. C 55 (1997) R553.

J.F. Briesmeister (Editor), Los Alamos National Laboratory, MCNP a General Monte Carlo Transport Code, LA-12625-M (1997) 2. Ch. Miehé et al., Eur. Phys. J. A 5 (1999) 143.

R. Kirchner, Nucl. Instr. and Meth. B 70 (1992) 186.

M. Santana-Leitner et al., Nucl. Instr. and Meth. A, To be published. M. Oinonen et al., Nucl. Phys. A 701 (2002) 613c. 
Table 1. Studied materials.

\begin{tabular}{|c|c|c|c|c|}
\hline Material & $\begin{array}{c}\text { Melting } \\
\text { point }\left[{ }^{\circ} \mathrm{C}\right]\end{array}$ & $\begin{array}{c}\text { Characteristic } \\
\text { size }[\mu \mathrm{m}]\end{array}$ & $\begin{array}{l}\text { Crucible } \\
\text { material }\end{array}$ & Supplier \\
\hline Ti foil & 1657 & 30 & $\mathrm{Ta}$ & Johnson Matthey \\
\hline $\mathrm{TiO}_{2}$ powder pellet $\left(2.4 \mathrm{~g} / \mathrm{cm}^{3}\right)^{\mathrm{a}}$ & 1850 & $<50$ & $\operatorname{Re}$ & Fluka $^{\mathrm{b}}$ \\
\hline $\mathrm{TiO}_{2}$ felt & 1850 & $\sim 6$ & $\operatorname{Re}$ & Home made [4] \\
\hline V foil & 1890 & 30 & $\mathrm{Ta}$ & Goodfellow \\
\hline VC powder pellet $\left(3.8 \mathrm{~g} / \mathrm{cm}^{3}\right)^{\mathrm{a}}$ & 2810 & $<44$ & $\mathrm{C}$ & Alfa ${ }^{c}$ \\
\hline $\mathrm{SrZrO}_{3}$ powder pellet $\left(3.4 \mathrm{~g} / \mathrm{cm}^{3}\right)^{\mathrm{a}}$ & 2750 & $<10$ & $\mathrm{Ta}$ & Aldrich $^{\mathrm{d}}$ \\
\hline $\mathrm{Y}_{2} \mathrm{O}_{3}$ powder pellet $\left(3.2 \mathrm{~g} / \mathrm{cm}^{3}\right)^{\mathrm{a}}$ & 2410 & $<25$ & $\mathrm{Ta}$ & Fluka $^{\mathrm{e}}$ \\
\hline $\mathrm{Y}_{2} \mathrm{O}_{3}$ felt & 2410 & $\sim 9$ & $\mathrm{Ta}$ & Zircar Zirconia \\
\hline $\mathrm{Zr}$ foil & 1852 & 127 & $\mathrm{Ta}$ & Ventron \\
\hline $\mathrm{ZrO}_{2}$ powder pellet $\left(2.9 \mathrm{~g} / \mathrm{cm}^{3}\right)^{\mathrm{a}}$ & 2700 & $50-100$ & $\mathrm{Ta}$ & Serva \\
\hline $\mathrm{ZrO}_{2}$ felt & 2700 & $\sim 9$ & $\mathrm{Ta}$ & Zircar Zirconia \\
\hline $\mathrm{Nb}$ foil & 2470 & 127 & $\mathrm{Ta}$ & Johnson Matthey \\
\hline Mo foil & 2624 & 50 & $\mathrm{Ta}$ & Goodfellow \\
\hline Ta foil & 2996 & 50 & $\mathrm{Ta}$ & Goodfellow \\
\hline
\end{tabular}

${ }^{\mathrm{a}}$ Made by pressing the powder.

${ }^{\mathrm{b}}$ Product No. 89490.

${ }^{\mathrm{c}}$ Stock No. 12141.

${ }^{\mathrm{d}}$ Catalogue No. 39,616-8.

${ }^{\mathrm{e}}$ Product No. 95832.

Table 2. Overview of target characteristics, operation conditions, release parameters (release is proportional to $\left.\left(1-\exp \left[-\ln 2 t / t_{\mathrm{r}}\right]\right)\left(\alpha \exp \left[-\ln 2 t / t_{\mathrm{f}}\right]+(1-\alpha) \exp \left[-\ln 2 t / t_{\mathrm{s}}\right]\right)[10]\right)$ and ionization efficiencies during the different on-line runs.

\begin{tabular}{|c|c|c|c|c|c|c|c|c|c|c|}
\hline \multirow[t]{2}{*}{ Element } & \multicolumn{3}{|c|}{ Target } & \multicolumn{2}{|c|}{ Line } & \multirow{2}{*}{$\begin{array}{c}\text { On-line } \\
\text { eff. } \\
\%\end{array}$} & \multicolumn{4}{|c|}{ Release } \\
\hline & & $\mathrm{g} / \mathrm{cm}^{2}$ & ${ }^{\circ} \mathrm{C}$ & & ${ }^{\circ} \mathrm{C}$ & & $\alpha$ & $\begin{array}{c}t_{\mathrm{r}} \\
\mathrm{ms}\end{array}$ & $\begin{array}{c}t_{\mathrm{f}} \\
\mathrm{ms}\end{array}$ & $\begin{array}{c}t_{\mathrm{s}} \\
\mathrm{s}\end{array}$ \\
\hline $\mathrm{Mn}$ & $\mathrm{ZrO}_{2}$ & 5.8 & 1800 & $\mathrm{~W}$ & 2150 & 10 & 0.72 & 20 & 256 & 11.2 \\
\hline Mn & $\mathrm{Nb}$ & 50 & 2050 & $\mathrm{~W}$ & 2450 & 19 & 0.9996 & 42 & 31000 & 95 \\
\hline $\mathrm{Kr}$ & $\mathrm{SrO}$ & 18 & 1460 & MK7 & 2080 & 3 & 0.78 & 67 & 397 & 3.89 \\
\hline $\mathrm{Kr}$ & $\mathrm{ZrO}_{2}$ & 8 & 1850 & MK7 & 2020 & 3 & 0.71 & 90 & 938 & 12.7 \\
\hline $\mathrm{Kr}$ & $\mathrm{Nb}$ & 42 & 1900 & MK7 & 1900 & 9 & 0.82 & 75 & 829 & 23.1 \\
\hline
\end{tabular}




\section{Figure captions}

Fig. 1. Release of species from materials as a function of temperature $(a, c)$ and heating time $(b, d, e)$.

Fig. 2. (a) The yields $(\boldsymbol{\Lambda}, \boldsymbol{\square})$ and in-target production yields $(\Delta, \square)$ (see definition [13]) of Mn nuclei from a $\mathrm{Nb}$ foil and $\mathrm{ZrO}_{2}$ felt targets. (b) The yields $(\bullet, \boldsymbol{\bullet}, \mathbf{\Delta})$ and in-target production yields $(\circ, \square, \Delta)$ of $\mathrm{Kr}$ nuclei from a $\mathrm{SrO}$, $\mathrm{ZrO}_{2}$ felt and $\mathrm{Nb}$ foil targets.

Fig. 3. Experimental (solid line) and simulated (up and down triangles) effusion delay time distributions for $\mathrm{Kr}$ from a $\mathrm{Nb}$ foil target. In the inset measured (squares) and calculated (circles) on-line release curves for ${ }^{73} \mathrm{Kr}$ from a $\mathrm{Nb}$ foil target. 

